\title{
Vibration Signal Analysis for Cave Detection as Basic of Developing Pump Operations: Case Study Unit Distillation PLN Belawan
}

\author{
${ }^{1}$ M. Z.Lubis, ${ }^{2}$ I. Isranuri \\ Mechanical Engineering Department, University of North Sumatera, Medan, Indonesia \\ Email: lubiszukhri@gmail.com
}

\begin{abstract}
Cavitation occurs due to the formation of empty cavities in the fluid flow that decreases pressure quickly. When cavitation occurs then the pump performance will decrease marked with noise and when this condition is not addressed will cause damage to the pump components. The distillation pump working under vacuum pressure and working temperature at $38^{\circ} \mathrm{C}$ is susceptible to cavitation. The pressure and temperature conditions of this distillation pump work result in faster fluid evaporation and eventually trigger cavitation. To avoid the occurrence of cavitation, it must be known operational limits concerning the pressure and working capacity of the distillation pump. The operational limit of this pump is between the shut-off point meaning there is no flow and run-out point which means the full capacity of the pump. This study aims to determine the operating limits of safe distillation pumps both from pressure and capacity. The experimental methodology used is to vary the capacity of the pump by adjusting the opening valve discharge at $100 \%, 90 \%, 80 \%$ and $70 \%$ capacities. Then for each capacity varied also the suction pressure of pump at $0 \mathrm{mmHg},-7 \mathrm{mmHg},-15 \mathrm{mmHg}$ and $-22 \mathrm{mmHg}$ by arranging vacuum pump. The magnitude of the vibration response is measured to determine the effect of the capacity and variation of pump suction pressure. With this method can be known range of capacity and pressure suction safe for operation of distillation pump. The results showed that the highest vibration value was in the axial direction. Vibration spectrum value spread over the range $1600-1900 \mathrm{~Hz}$ with the highest value is at $100 \%$ capacity $(0.00278 \mathrm{~m} 3 / \mathrm{sec})$ suction pressure $-0 \mathrm{mmHg}$ with amplitude of $0.410 \mathrm{~g}$ at $1660 \mathrm{~Hz}$ frequency. While the lowest vibration value is at a flow rate of $0.00208 \mathrm{~m} 3 / \mathrm{sec}$ with an amplitude of $0.210 \mathrm{~g}$ at a frequency of $1816 \mathrm{~Hz}$. While the minimum flow rate to avoid the occurrence of cavitation due to recirculation flow is equal to $0.00172 \mathrm{~m} 3 / \mathrm{sec}$.
\end{abstract}

Keywords cavitation, distillation pump, operational limit, valve discharge, vacuum pump Paper type Research paper

\section{INTRODUCTION}

The pump is a fluid engine used as a means of transportation fluid from one place to another by providing fluid mechanical energy. Additional mechanical energy is used to increase speed, pressure and fluid elevation as well as to overcome the flow resistance along the pump installation pipe. The fluid transferred by the pump is a fluid that is incompressible (incompressible fluids) and as long as the transportation process density doesn't change a lot.

Centrifugal pump is one type of pump that is widely used in the industrial world such as power plant, petroleum, water processing and distribution and waste treatment.

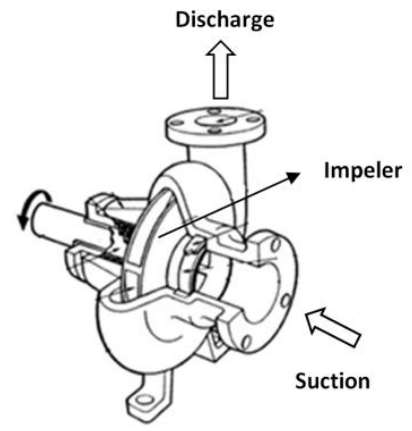


Figure 1 The Basic Principle of Centrifugal Pump(www.nuclear-power.net)

Centrifugal pump works with the principle of rotation impeller as a liquid fluid transfer element which is driven by a prime mover.The liquid will rotate by the impulse impulse of the impeller giving the centrifugal force so that the liquid flows from the center of the impeller, out through the blade duct, and leave the impeller at high speed.

High-speed liquid then passes the channel that the cross-section becomes larger so that there is a change of head (high press) speed to head pressure. Once the liquid is thrown by the impeller, the space between the blades becomes vacuum so that the liquid is inhaled and the suction process occurs. The simple construction and easy operation of centrifugal pumps is one of the foundations in the determination of pumps, so this type of pump is widely selected and applied in the industrial world. Given the role of centrifugal pumps that are very important in industrial processes and can potentially interfere with performance production system as a whole, it is necessary to keep these pumps operating reliably with high performance. One application of centrifugal pumps in the industrial world is as a distillation pump at the desalination plant. This installation treats sea water into fresh water by evaporation process (evaporation). In this installation, the pump serves to pump the distillate liquid from the distillate tank, with vacuum pressure and ambient temperature above, into the heap tank. The distillation pump operates under vacuum pressure and above the ambient temperature so that it may experience cavitation. Cavitation on the centrifugal pump will result in damage to the pump components, the sudden drop of performance, the instability in the pump operation and decrease the reliability of the system.

There has been many research and testing of cavitation phenomena on centrifugal pumps with emphasis on different aspects, those are:

J.Jeremy dan K.Dayton [1], conducting experiments to detect cavitation occurring on a centrifugal pump. Observations were made at the dynamic inlet pressure on the inlet by using the noise indicator. This study shows that the emergence of noise is an early indication of the occurrence of cavitation in the pump and this method can be used to determine the wear of the ring.

Theodorus Bayu Hanandoko [2], examine the initial symptoms that appear to the process of cavitation, the results of this study indicate that the cavitation that occurs causes noise, vibration, decreased performance and impeller damage.

D. Gultom [3] doing research on the effect of pressure and temperature on cavitation. This study shows the effect of pressure and temperature on the occurrence of cavitation.

Friedrichs dan Kosyna [4], do a research flow velocity between the impeller blades. Flow velocity is too high due to uncontrolled discharge increase, resulting in blocked flow resulting in lower pump capacity. This study shows the relationship of cavitation index ( $\sigma i)$ with head coefficient $(\psi)$ on a centrifugal pump.

Delgosha [5] conducting experiments with flow visualization on centrifugal pumps in cavitation and non-cavitation conditions. Research shows the relationship between head drop with NPSH. As the NPSH decreases the bubbles appear more clearly.

Richmond [6], conducting tests on centrifugal pumps under different operational conditions. Observations are made on the vibrations and air bubbles that occur.

IrhamSuyanto [7] conducted an experimental experimental study of cavitation phenomena on centrifugal pump blades. In this study the parameters used to observe the occurrence of cavitation is the Thoma number $(\sigma)$, it was concluded that cavitation at centrifugal pump blades increased in intensity at low cavitation rates caused by low suction pressure, high fluid temperature, rotation and large capacity.

From studies done by some previous researchers, it appears that cavitation starts[8][9]. From the emergence of bubbles of vapor due to pressure drops or rise in temperature of the liquid either in the pump or in the pump installation. On this opportunity the author tries to do research to know the operating conditions, especially the capacity and pressure suction that can cause the occurrence of cavitation at the distillation pump. Variations in pump capacity, suction pressure and vibration measurements were generated at the pump.

This research is to know the safe operation limits of cavitation on centrifugal pumps especially those operating with closed suction tanks and temperatures above the ambient by identifying vibrations at the pump using vibration signals by adjusting the capacity and suction pressure.

Providing information on safe operation, especially with the capacity and suction pressure of the pump to minimize the cavitation level on the operation of the distillation pump, this method can be applied as part of the condition base maintenance to improve the reliability of the pump operation[10][11]. Cavitation is a change phenomenon of fluid in the pump from the liquid to the vapor due to a decrease in localized static pressure under the vapor pressure of the liquid. The vapor formed, at sufficient volume, will limit the flow of the impeller fluid.

Cavitation on centrifugal pumps causes mechanical damage to the pump elements such as impellers, bearings, seals, casing in the form of erosion, corrosion and the sound of beats that cause vibration [12]. 
Cavitation also results in a decrease in pump performance marked by high-pressure drop and capacity. The vibration response of the pump in operation can be used as an indicator that gives an idea of the pump mechanical condition. Things that move simple harmonic on a simple swing have periods [13]. The swing period (T) is the time it takes for an object to perform one vibration. The object is said to do one vibration if the object moves from the point where it starts to move and returns to that point, as shown in Figure 2.8. below. (Pain, 2005)

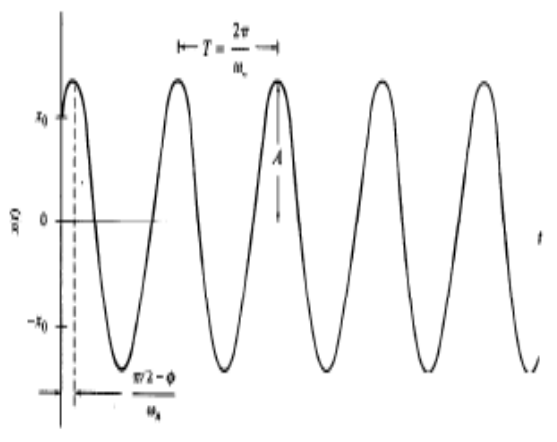

Figure 2: Free Movement Response

According to the figure above the relationship between frequency and period by using equations as equation below:

$$
T=\frac{1}{f}
$$

And the angular velocity can be calculated by the equation below:

$$
\omega=2 \pi f \sqrt{\frac{k}{m}}
$$

In harmonic motion, the relation between the maximum displacement and time can be calculated through the equation as follows:

$$
x=X \sin \omega t
$$

For speed, using the derivatives of equation (2.3) above can be calculated by the following equation:

$$
x^{\prime}=\omega A \cos \omega t
$$

Using the derivatives of equation (2.4) above then acceleration can be calculated by the following equation:

$$
x^{\prime \prime}=-\omega^{2} A \sin \omega t
$$

To analyze the vibration pattern, used time-response and frequency domain analysis.
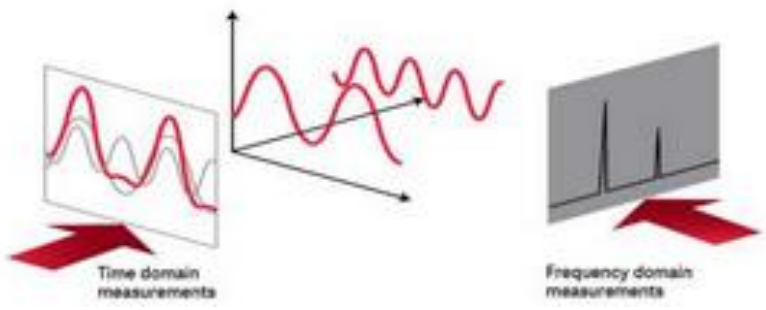

Figure 3 Connection between sine signals in Time domain and Frequency domain (www.eletime.com). 
The time domain of a system involves the measurement data of the vibration signal monitoring object, the working fluid pressure, the working fluid temperature and the fluid signal flow, while the frequency domain will give information will give one or more separate frequencies, where the vibration energy point is centered then the dynamic characteristics of a component the system will be known [14][15].

Cavitation at the pump occurs, among others, due to the drop in operatic pressure under the vapor pressure of saturated liquids, turbulence, pulses and conditions under which NPSHa<NPSHr.

The Net Positive Suction Head Available (NPSHa) installed pump is determined based on the installed installation with the following equation [16]:

$$
\mathrm{NPSH}_{a}=\frac{P_{a}}{\gamma}-\frac{P_{v}}{\gamma} \pm h_{s t}-h_{h l}
$$

Which:

$\mathrm{Pa} \quad$ : Tank Pressure (m)

$\mathrm{Pv} \quad$ : Saturated vapor pressure $(\mathrm{m})$

$\gamma \quad: \quad$ Weight of liquid type $(\mathrm{kg} / \mathrm{m} 3)$

hst : static suction head (m)

hhl : head loss (m)

Cavitation can also be caused by the flow of recirculation in the impeller, caused by backflow. The return flow on the suction side occurs because the pump works under its minimum flow. The minimum pump flow depends on the impeller design and can be determined as bellow:

$$
\begin{array}{ll}
\mathrm{F} & : \mathrm{B} \times \mathrm{w} \times \Sigma \text { Vane } \\
\text { Sin } \beta 1 & : 1,273 \times \mathrm{F} 1 /(\mathrm{D} 22)-(\mathrm{h} 12) \\
\text { Qmin } & \left.\left.: \text { D1 (D22)-(h, }{ }_{1}^{2}\right) \times \mathrm{rpm} / 93,45\right) \times(\mathrm{Ve} / \mathrm{Ui})
\end{array}
$$

\section{Which:}

$F \quad$ : Area of inlet water to the impeller

$B \quad$ : Gap on the incoming side of the impeller

$w \quad$ : The gap between the impeller blades on the entry side

$\operatorname{Sin} \beta 1$ : Angle between Ve and Ui on the entry side

$D_{1} \quad$ : Inner diameter of impeller

$D_{2} \quad$ : Outlet diameter of the impeller

h1 : Distance from the center of the shaft to the hole of the impeller hole

Ve : absolute speed

Ui : Speed peripherals

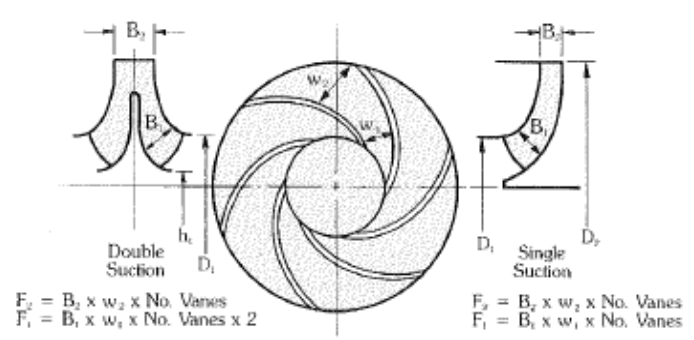

Figure 4 The diagram specifies the fluid including the impeller 


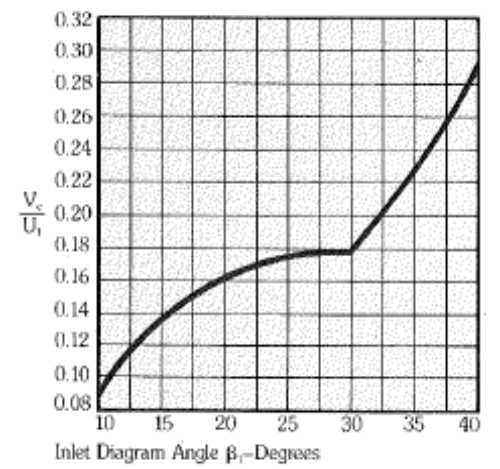

Figure 5 The diagram specifies Ve / Uivs $\beta 1$

\section{METHOD}

The experiments were carried out with the installed centrifugal pump conditions installed according to Table 1. The pump model technical data as bellow:

\begin{tabular}{|l|c|l|}
\hline \multicolumn{1}{|c|}{ Uraian } & Satuan & \multicolumn{1}{c|}{ Nilai } \\
\hline \hline Head & $\mathrm{m}$ & 9,28 \\
Kapasitas & 1tr/sec & 2,8 \\
Daya & Watt & 746 \\
Putaran & $\mathrm{rpm}$ & 1450 \\
Din & $\mathrm{mm}$ & 59,5 \\
Dout & $\mathrm{mm}$ & 165,6 \\
Bi & $\mathrm{mm}$ & 13 \\
$\beta \mathrm{i}$ & $\mathrm{deg}$. & 17 \\
$\Sigma$ Vane & $\mathrm{bh}$ & 4 \\
$\mathrm{~h}$ & $\mathrm{~mm}$ & 16,5 \\
\hline
\end{tabular}

Tabel 1 Impeller technical data

In this experimental system, the pump discharges water at a closed installation where the flow rate is measured by a flow meter. The absolute static pressure on the tank is reduced gradually by means of a vacuum pump.

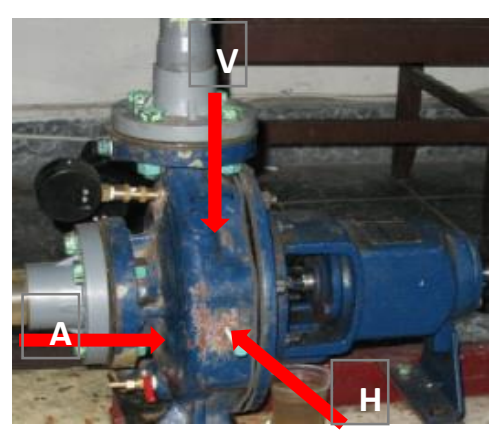

(a)

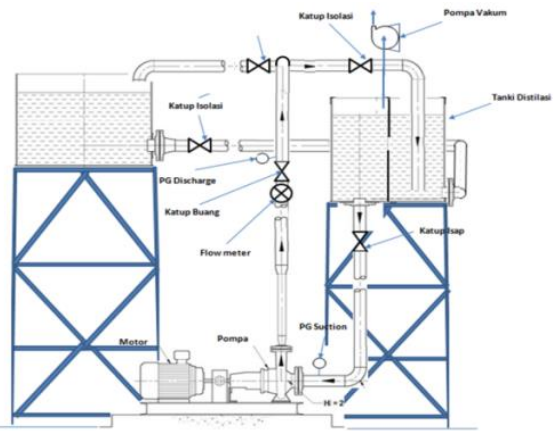

(b)

Figure 6: (a) Position of vibration measurement and (b) Research installation

The position of the accelerometer is placed in the axial, vertical and horizontal direction of the pump case as shown in Figure 7. During the data retrieval process the speed of pump rotation and water temperature is maintained constant. The first experiment was carried out by measuring the shut-off position to the run-out position of the pump until the pump characteristics curve and its installation were obtained. 


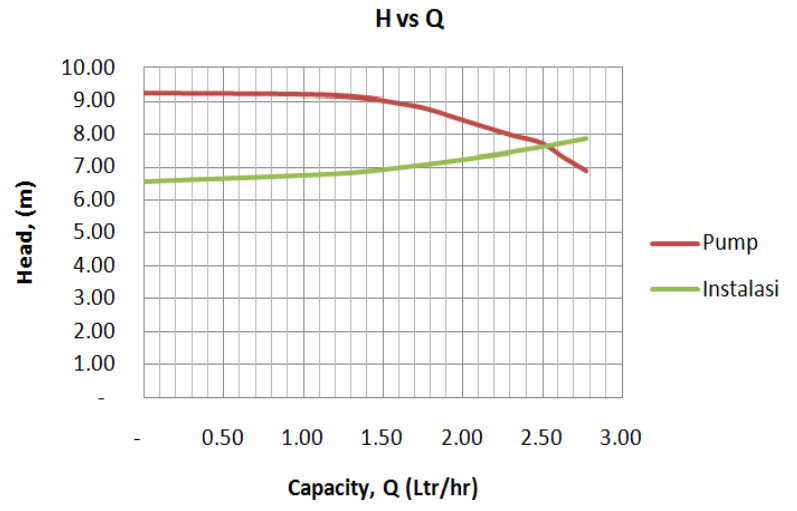

Figure 8 Pumps Characteristics

In the experimental line, the accelerometer used is DI-440 SKF.

Implementation of the experiment begins by checking (line up) the readiness of all installations, equipment, measuring tools installed and water in the tank. Then the pump is turned on for a while, after normal circulation measurement of shaft rotation with tachometer and measuring water temperature with thermometer up to $380 \mathrm{C}$. Further testing to determine the characteristics of the pump with variation of capacity and for each capacity do also variations of suction pressure and do the measurement of vibration response.

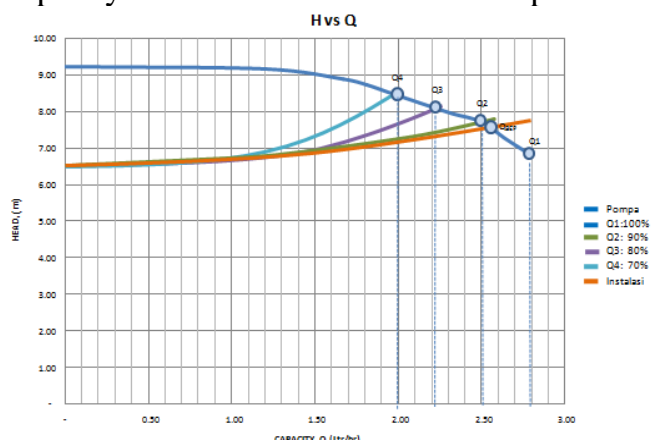

Figure 9 Pump test plan with capacity variation and suction pressure

\section{DISCUSSION}

From the experimental results obtained data that the highest vibration amplitude is in the axial direction as shown in the figure 10 below:

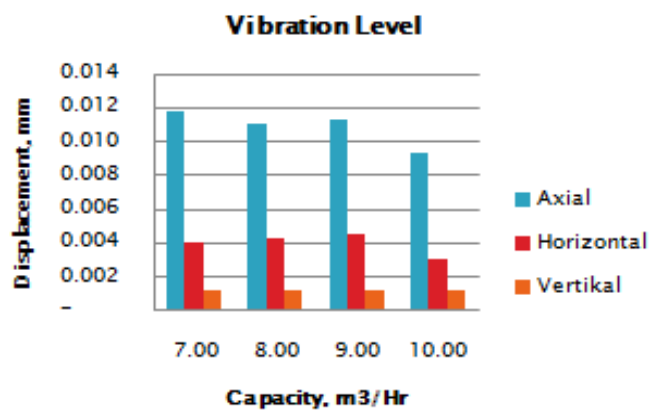

(a) 


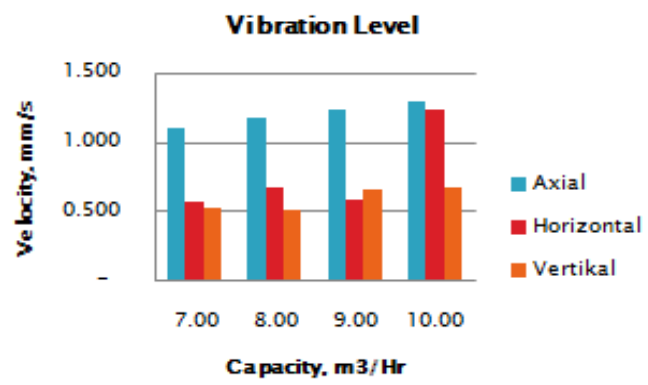

(b)

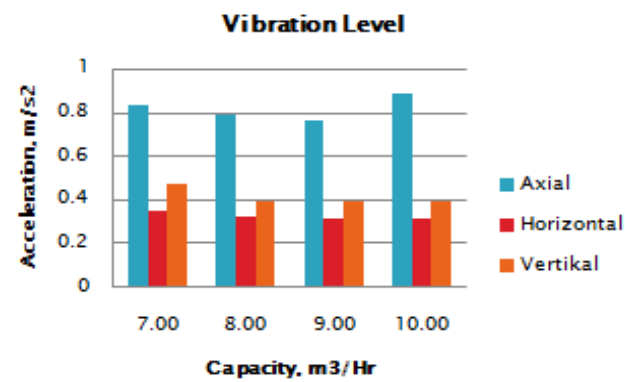

(c)

Figure 10 Diagram of the measurement results of the pump vibration response

Characteristics of Shaking on Time Domains

By figure 11 it shows that there is an amplitude increase with the highest value up to $1.4117 \mathrm{~m} / \mathrm{s} 2$ with a period of $0.60 \mathrm{sec}$ at a suction pressure of 0.7 bar A compared with an amplitude value of $0.9932 \mathrm{~m} / \mathrm{s} 2$ and a period of $0.80 \mathrm{sec}$ at suction pressure $-0 \mathrm{mmHg}$.

At suction pressure $-150 \mathrm{mmHg}$, the amplitude reaches $1.0601 \mathrm{~m} / \mathrm{s} 2$ with a period of $0.38 \mathrm{sec}$, whereas at a suction $-70 \mathrm{mmHg}$ suction pressure is at the lowest value reaching $0.7136 \mathrm{~m} / \mathrm{s} 2$ with a period of $0.21 \mathrm{sec}$.

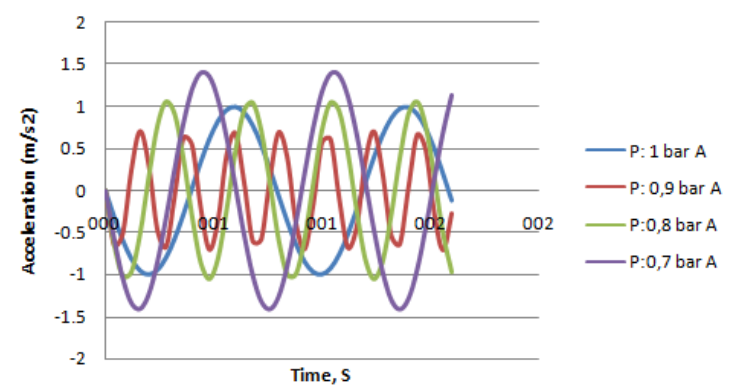

Figure 11: Characteristics of vibration at capacity $100 \%$

By figure: 12 it appears that at the pressure of suction 1 bar the amplitude value is $1.2072 \mathrm{~m} / \mathrm{s} 2$ and the period is $0.25 \mathrm{sec}$. At a suction pressure of $-70 \mathrm{mmHg}$, the amplitude occurring is at the lowest value of $0.8223 \mathrm{~m} / \mathrm{s} 2$ with a period of $0.24 \mathrm{sec}$.

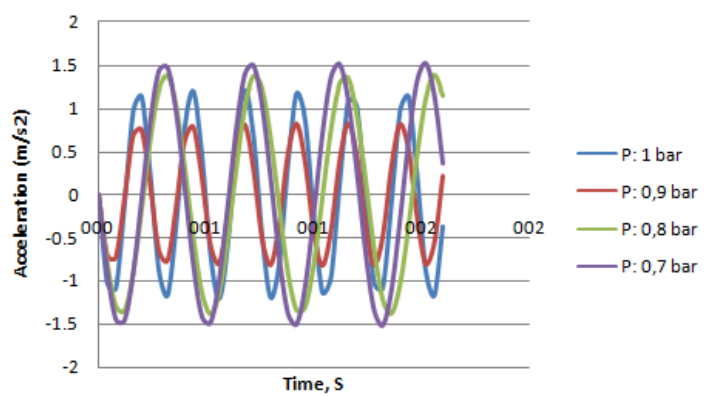

Figure 12: Characteristics of vibration at capacity $90 \%$ 
Then at suction pressure 0.8 , there is an amplitude increase back up to $1.3814 \mathrm{~m} / \mathrm{s} 2$ with a period of $0.43 \mathrm{sec}$. The highest amplitude occurs at a suction pressure of $-220 \mathrm{mmHg}$ of $1.5325 \mathrm{~m} / \mathrm{s} 2$ and a period of $0.42 \mathrm{sec}$.

By Figure 13 it is seen that at a suction pressure of $-0 \mathrm{mmHg}$, the amplitude is at $1.1886 \mathrm{~m} / \mathrm{s} 2$ with a period of $0.24 \mathrm{sec}$.

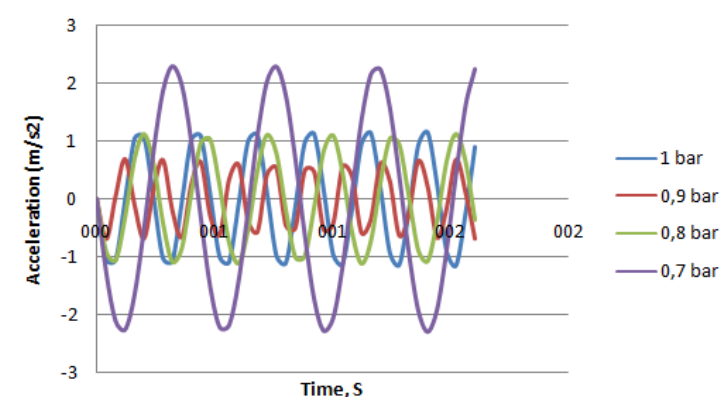

Figure13: Characteristics of vibration at capacity $80 \%$

While at suction pressure $-70 \mathrm{mmHg}$ the amplitude drops and reaches the lowest value, ie $0.6937 \mathrm{~m} /$ $\mathrm{s} 2$ with a period of $0.16 \mathrm{sec}$. The highest amplitude was $2.2995 \mathrm{~m} / \mathrm{s} 2$ with a period of $0.27 \mathrm{sec}$ at a suction pressure of $-150 \mathrm{mmHg}$, whereas at suction pressure $-220 \mathrm{mmHg}$ the amplitude drops again and is at a value of $1.1161 \mathrm{~m} / \mathrm{s} 2$ with a period of $0.47 \mathrm{sec}$.

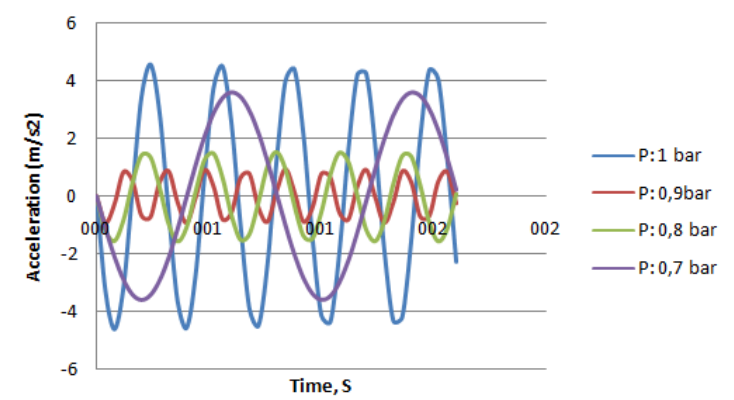

Figure13: Characteristics of vibration at capacity $70 \%$

By Figure 14 it shows that the highest amplitudes are $4,5936 \mathrm{~m} / \mathrm{s} 2$ with a period of $0.32 \mathrm{sec}$ at suction pressure of $-0 \mathrm{mmHg}$. At the suction pressure of $-70 \mathrm{mmHg}$, the amplitude drops and reaches the lowest value of $0.9375 \mathrm{~m} / \mathrm{s} 2$ with a period of $0.18 \mathrm{sec}$, whereas at suction pressure $-150 \mathrm{mmHg}$ the amplitude rises again and is at a value reaching $1.5416 \mathrm{~m} / \mathrm{s} 2$ with a period $0.29 \mathrm{sec}$. At suction pressure $-220 \mathrm{mmHg}$ the amplitude grew to reach $3.5876 \mathrm{~m} / \mathrm{s} 2$ and the highest period reached $0.80 \mathrm{sec}$.

Characteristics Vibration in vibration spectrum

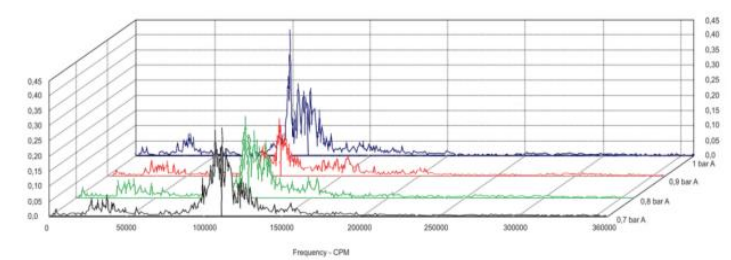

Figure 15: Spectrum of vibration at capacity at $100 \%$

From figure 15 above, it is seen that at $100 \%$ capacity and suction pressure of $0 \mathrm{mmHg}$, the highest vibration amplitude value is $0.410 \mathrm{~g}$ at a frequency of about $1660 \mathrm{~Hz}$ and a capacity of $10 \mathrm{~m} 3 / \mathrm{hr}$. At this maximum suction capacity and pressure, the valve discharge is fully open, allowing the liquid to enter the pump casing at a large rate and collide with the pump impeller and cause considerable vibration with maximum amplitude. At a suction pressure of $0 \mathrm{mmHg}$, the highest vibration amplitude value is $0.175 \mathrm{~m} / \mathrm{s} 2$ at a frequency of about $1880 \mathrm{~Hz}$ and a capacity of $9.29 \mathrm{~m} 3 / \mathrm{hr}$. At suction pressure $-15 \mathrm{mmHg}$, the highest vibration amplitude value is $0.225 \mathrm{~g}$ at a frequency of about $1830 \mathrm{~Hz}$ and a capacity of $8.55 \mathrm{~m} 3 / \mathrm{h}$. At a suction -22 $\mathrm{mmHg}$ pressure, the highest vibration amplitude value is $0.240 \mathrm{~g}$ at a frequency of about $1900 \mathrm{~Hz}$ and capacity $6.92 \mathrm{~m} 3 / \mathrm{hr}$. Decreasing suction pressure up to $-7 \mathrm{mmHg}$ reduces the rate of liquid entering the pump casing. 


\section{Vibration Signal Analysis for Cave Detection as Basic Of Developing Pump Operations: Case Study Unit Distillation PLN Belawan}

This causes the mass of the fluid to decrease as well, reducing the amount of impact with the vibration impeller and the decreasing amplitude. However, further reductions in suction pressure up to $-150 \mathrm{mmHg}$, in addition to decreasing pumping capacity also increase vibration. At a decrease of up to $-220 \mathrm{mmHg}$ also causes a significant decrease in capacity. From figure 16 below, it is seen that at $90 \%$ capacity and absolute pressure 1 bar absolute, the overall acceleration value is $0.788 \mathrm{~m} / \mathrm{s} 2$ with the highest vibration amplitude being $0.275 \mathrm{~m} /$ s2 at a frequency of about $1770 \mathrm{~Hz}$ and a capacity of $9.0 \mathrm{~m} 3 / \mathrm{h}$. Capacity arrangement is performed by adjusting the valve discharge opening so that the flow rate is reduced because the passageway is partially closed by the valve.

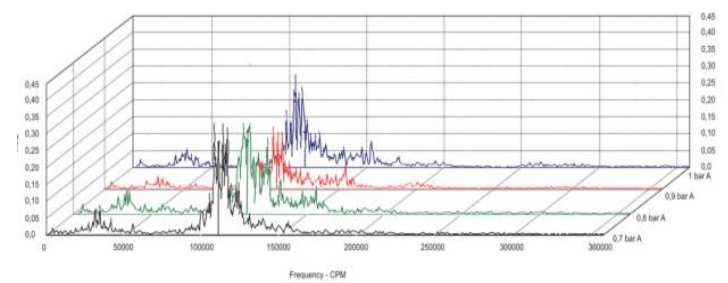

Figure 16: Spectrum of vibration capacity at $90 \%$

At decreasing suction pressure up to 0.9 bar the highest vibration amplitude value is $0,240 \mathrm{~g}$ at frequency around $1830 \mathrm{~Hz}$ and capacity $8,33 \mathrm{~m} 3$ / hour. At a suction pressure of 0.8 bar absolute, the highest vibration amplitude value is $0.210 \mathrm{~g}$ at a frequency of about $1816 \mathrm{~Hz}$ and a capacity of $7.50 \mathrm{~m} 3 /$ hour. At a suction pressure of $0.7 \mathrm{bar}$, the highest vibration amplitude value is $0.300 \mathrm{~g}$ at a frequency of about $1900 \mathrm{~Hz}$ and a capacity of $6.00 \mathrm{~m} 3$ / hour. Reduced capacity by strangulation on the discharge side will cause backflow or recirculation, both on the suction side and on the discharge side.

By the vibration spectrum above analysis that $90 \%$ capacity of pressure variation it is seen that the highest acceleration vibration response at a pressure of $220 \mathrm{~mm} \mathrm{Hg}$ with an amplitude value of $0.300 \mathrm{~g}$ and the lowest is at a pressure of $-70 \mathrm{mmHg}$ bar with an amplitude value of $0.240 \mathrm{~g}$.

By Figure 17 bellow, it is seen that at $80 \%$ capacity and suction pressure of $0 \mathrm{mmHg}$, the highest vibration amplitude value is $0.245 \mathrm{~g}$ at a frequency of about $1850 \mathrm{~Hz}$ and a capacity of $8.0 \mathrm{~m} 3$ / hour. Capacity arrangement is performed by adjusting the valve discharge opening so that the rate the flow is reduced because the pass is partially closed by the valve. At decreasing suction pressure up to $-70 \mathrm{mmHg}$ the highest vibration amplitude value is $0.230 \mathrm{~g}$ at a frequency of about $1920 \mathrm{~Hz}$ and a capacity of $7.13 \mathrm{~m} 3$ / hour. At a suction pressure of $-150 \mathrm{mmHg}$, the highest vibration amplitude value is $0.340 \mathrm{~g}$ at a frequency of about $1790 \mathrm{~Hz}$ and a capacity of $6.18 \mathrm{~m} 3 /$ hour.

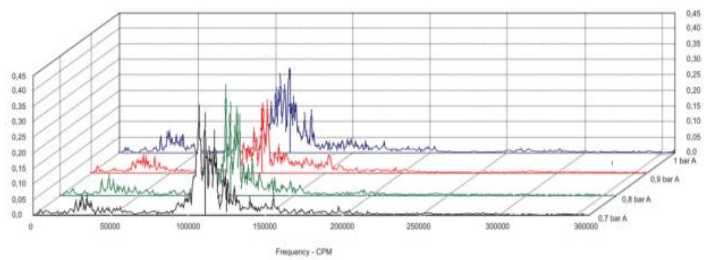

Figure 17: Spectrum of vibration capacity at $80 \%$

At a suction pressure of $-220 \mathrm{mmHg}$, the highest vibration amplitude value is $0.375 \mathrm{~g}$ at a frequency of about $1790 \mathrm{~Hz}$ and a capacity of $4.50 \mathrm{~m} 3 / \mathrm{hr}$. Reduced capacity by strangulation on the discharge side will cause backflow or recirculation, both on the suction side and on the discharge side. From the above vibration spectrum analysis for $80 \%$ capacity with pressure variation it is seen that the amplitude of the highest acceleration vibration response at a pressure of $220 \mathrm{mmHg}$ with an amplitude value of $0.375 \mathrm{~g}$ and the lowest is at a pressure of $-70 \mathrm{mmHg}$ with an amplitude value of $0.230 \mathrm{~g}$.

From the picture below, it is seen that at $70 \%$ capacity and suction pressure of $0 \mathrm{mmHg}$, the highest vibration amplitude value is $0.351 \mathrm{~g}$ at a frequency of about $1700 \mathrm{~Hz}$ and a capacity of $7.0 \mathrm{~m} 3 /$ hour.

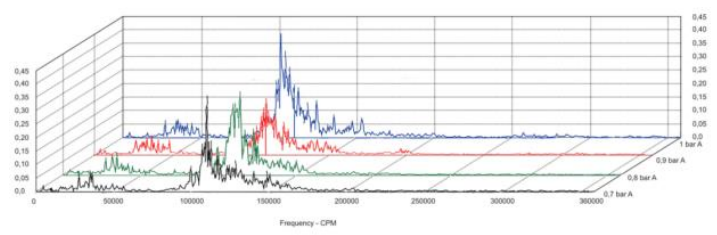


Figure 18: Spectrum of vibration at capacity $70 \%$

Capacity setting is done by adjusting the valve discharge opening so that the flow rate is reduced because the passageway is partially closed by the valve. At a suction pressure drop to $-70 \mathrm{mmHg}$ the highest vibration amplitude value is $0.225 \mathrm{~g}$ at a frequency of about $1850 \mathrm{~Hz}$ and a capacity of $6.24 \mathrm{~m} 3$ / hour. At a suction pressure of $-150 \mathrm{mmHg}$, the highest vibration amplitude value is $0.310 \mathrm{~g}$ at a frequency of about 1900 $\mathrm{Hz}$ and a capacity of $4.86 \mathrm{~m} 3 / \mathrm{h}$. At a suction $-220 \mathrm{mmHg}$ pressure, the highest vibration amplitude value is $0.350 \mathrm{~g}$ at a frequency of about $1880 \mathrm{~Hz}$ and capacity $3.46 \mathrm{~m} 3$ / hour. Reduced capacity by strangulation on the discharge side will cause backflow or recirculation, both on the suction side and on the discharge side.By analysis of vibration spectrum above amount $70 \%$ capacity with pressure variation it is seen that the highest acceleration vibration response at $-220 \mathrm{mmHg}$ pressure with the amplitude value of $0.350 \mathrm{~g}$ and the lowest is at $70 \mathrm{mmHg}$ pressure with an amplitude value of $0.230 \mathrm{~g}$. By the results of the above analysis, it can be determined the range of operations for the distillation pump as Table 2 bellow:

\begin{tabular}{|c|c|c|c|c|c|c|c|c|}
\hline Kapasitas & & Pressure & & Q & $A_{\max }$ & NPSHa & NRe & Keterangan \\
\hline$Q(m 3 / h r)$ & $\begin{array}{l}\text { Suction } \\
(\mathrm{mmHg})\end{array}$ & $\begin{array}{c}\text { Disc. } \\
(\mathrm{kg} / \mathrm{cm} 2)\end{array}$ & $\begin{array}{l}\text { Vakum } \\
\text { (mmHg) }\end{array}$ & (\%) & (g) & (m) & & \\
\hline 0.002580 & -7 & 0.40 & -120 & 100 & 0.175 & 10.32 & 119,372 & Operasi Intermit \\
\hline 0.002375 & -15 & 0.34 & -280 & 100 & 0.225 & 9.26 & 109,213 & Operasi Intermit \\
\hline 0.002500 & 0 & 0.64 & -5 & 90 & 0.275 & 11.24 & 128,325 & Operasi Kontinyu \\
\hline 0.002315 & -7 & 0.46 & -140 & 90 & 0.240 & 10.34 & 106,937 & Operasi Kontinyu \\
\hline 0.002083 & -15 & 0.38 & -290 & 90 & 0.210 & 9.28 & 95,055 & Operasi Kontinyu \\
\hline 0.002222 & 0 & 0.70 & -5 & 80 & 0.245 & 11.26 & 114,067 & Operasi Kontinyu \\
\hline 0.001980 & -7 & 0.50 & -120 & 80 & 0.230 & 10.36 & 31,661 & Operasi Kontinyu \\
\hline 0.001944 & 0 & 0.78 & -7 & 70 & 0.351 & 11.29 & 99,808 & Operasi Intermit \\
\hline 0.001733 & -7 & 0.52 & -130 & 70 & 0.225 & 10.37 & 80,203 & Operasi Intermit \\
\hline
\end{tabular}

Table 2: Operation Range Distillation Pump

\section{CONCLUSION}

From the research results it can be seen that at suction pressure $-220 \mathrm{mmHg}$ according to the parameters of operation, the pump starts to experience cavitation. The continuous operating range of a safe distillation pump is at a $90 \%$ capacity with suction pressure $0 ;-70 ;-220 \mathrm{mmHg}$ and $80 \%$ capacity with suction pressure from 0 to $70 \mathrm{mmHg}$. The intermittent operating range is at $100 \%$ capacity with suction pressure $(-70--150) \mathrm{mmHg}$ and $70 \%$ capacity with suction pressure $(0--70) \mathrm{mmHg}$. The operation of the distillation pump with the smallest vibration level is at $100 \%$ capacity with $0.175 \mathrm{~g}$ amplitudes at suction pressure of $-70 \mathrm{mmHg}$ and the largest vibration level is at $100 \%$ capacity with amplitude $0.410 \mathrm{~g}$. This value continues to decline at a capacity of $90 \%$ - $80 \%$ and begins to increase at $70 \%$ capacity. Operation of a safe and continuous distillation pump is at suction pressure $(0-150) \mathrm{mmHg}$ for $90 \%$ capacity and $(0-70) \mathrm{mmHg}$ for $80 \%$ capacity. For safe operation but intermit at $100 \%$ capacity is at suction pressure $(-70--150) \mathrm{mmHg}$ while at $70 \%$ capacity is $(0--70) \mathrm{mmHg}$.

\section{References}

[1] J.Jeremy and D. Kenwood.Detecting Cavitation in Centrifugal Pumps.Experimental Results of the Pump Laboratory. 2000.

[2] Hanandoko.TB. Deteksi Instalasi Pompa Sentrifugal Terhadap Gejala Kavitasi. Jurnal Teknologi Industri Vol.IV.2000

[3] Gultom.D. Study EksperimenPengaruhTekanandanTemperaturpadaKavitasi.TeknikMesin ITS.2001

[4] Friedrich. Centrifugal Pump Vibration Caused by Supersynchronous Shaft Instability.1996.

[5] Delgosha, Coutier. A Numerical Study of Cavitation Induced Vibration. 2015.

[6] Richmond, V. A. Air Bubble and Cavitation Vibration Signatures of a Centrifugal Pump.SpectraQuest Inc. 2006.

[7] Suyanto, Irham, 2005, "StudiEksperimentalFenomenaKavitasiPadaSuduPompaSentrifugal", TugasAkhir: ITS.2005

[8] Schiavello, B. Cavitation and Recirculation Troubleshooting. Proceedings of The TenthInternational Pump Users Symposium. New Jersey. 1996

[9] Schiavello, B and Cicatelli, G. Vibration Field Problem Resolved with analytical Diagnostics Approach and Innovative Impeller Design. Proceedings of The Twenty-thirdInternational Pump Users Symposium. New Jersey. 2007

[10] Bakri, Syaiful.,Sunarya, N., dan Alibasyah, S. IAnalisa Kondisi Pompa Sekunder dan Primer RSG G>A. Siwabessy dengan pemantauan Vibrasi Overall. Prosiding Seminar Hasil Penelitian P2TRR. 2004.

[11] Girdhar, P. danOctoMoniz.Practical Centrifugal Pumps Design, Operation and Maintenance.Netherlands,IDC Technologies.2005

[12] K. A. Mohammed. Cavitation in CentripugalPumps.Diyala Journal of Engineering .College of Engineering - University of Diyala. 2010

[13] Pain, H. J. The Physics of Vibrations and Waves.6th Edition. London, John Wiley \& Sons, Ltd. 2005.

[14] Schiavello, B and Visser, F. C. Pump Cavitation - Various NPSHR Criteria, NPSHA Margins, and Impeller Life Expectancy. Proceedings of The Twenty Fifth International Pump Users Symposium. New Jersey. 2009

[15] R.Krishna and J Ellenberger. Influence of low Frequency Vibrations on Bubble and drop sizes formed at single orifice. Chemical Engineering and Processing. 2002. Scheffer, C. danGirdhar P. Practical Machinery Vibration Analysis and Predictive Maintenance. Netherlands.2002 